\title{
Association between some grain related traits of barley under drought and irrigated conditions
}

\author{
Halgurd Nasraden Hassan ${ }^{1}$, Masood Saber Mohammed ${ }^{1}$, Yadgar Ali Mahmood ${ }^{2}$ \\ 1 Kalar Technical Institute, Sulaimani Poly technic University, KRG-Iraq \\ 2 University of Garmian, Kalar, As Sulaymaniay ah, KRG-Iraq
}

\begin{abstract}
Under drought conditions, barley grain related traits are affected by water stress and reduced grain yield potential. Therefore, two experiments were carried out at the Kalar technical institute for two seasons of 2016-17 and 2017-18 testing five hybrid of tow-rowed barley (Hordeum vulgare L.) under irrigated and unirrigated conditions. Genotypes were assessed for thousand grain weight, grain filling duration and grains number per particular of spike length. The average of both years, drought significantly reduced thousand grain weight by $7.63 \mathrm{~g}$ and shortened grain filling duration by $44.3{ }^{\circ} \mathrm{Cd}$, but not affected grains number may due to genetically controlling this trait. Genotypes 3//4 and 3//14 scored highest values of thousand grain weight and grain filling duration under both irrigated and drought conditions. However, genotype 3//1 was least affected by drought for both thousand grain weight and grain filling duration indicating higher resistance against water stress for this genotype. Regression analysis showed a positive relationship between thousand grain weight and grain filling duration under both irrigated $\left(\mathrm{R}^{2}=0.85 ; \mathrm{P}=0.03\right)$ and unirrigated $\left(\mathrm{R}^{2}=0.80 ; \mathrm{P}=0.04\right)$ conditions averaging over seasons showing the importance of post-anthesis period to increase the single grain weight. The correlation between thousand grain weight and grains number, however, was negative for the cross-year mean under drought conditions $\left(\mathrm{R}^{2}=0.75 ; \mathrm{P}=0.05\right)$ may due to the trade-off between these two traits.
\end{abstract}

\section{Introduction}

Barley is one of the most important cereals worldwide. Barley is used as whole grain or processed in making noodles, porridge and fortified infant foods and feed. First Iraqi domesticated barley was founded In the Jarmo village in about 6750 B.C. (Helbaek, 1953). The main goal in breeding process is the crop yield, which is valuated through the economic benefit of the producers. The yield is a function of genetic potential of the variety and external conditions in which the crop is grown. The first component which directly affects the barley yield is the number of spikes per $\mathrm{m}^{2}$ (Sinebo, 2002). The number of grains per spike is the second component, and the third component is 1000 grain weight (Evans and Wardlaw, 1976; Reid Wiebe, 1979). Increasing the number of grains per spike means reducing the grain weight per spike (Rasmussen and Chanel, 1970).

Barley is a crop which can grow in different environmental conditions, it is expected that each variety reacts differently according to the environmental conditions (Dimova, et al., 2006; Valcheva, et al., 2010). In order to determine the influence of environmental conditions on the genetic potential of each variety, it is necessary to evaluate the interaction between the environmental conditions and the genotype. Nowadays, there are many studies about the interaction between the grain yield of barley and environ mental conditions (Penchev, et al., 2002).

Drought is certainly the most prevalent and damaging abiotic stress of barley growth conditions (Alghabari, et al., 2015). Decreasing freshwater resources and low annual rainfall cause extreme drought events, especially at crop critical growth stages. The severity of drought stress is expected to be increasing day by day and it has been estimated that will cause severe losses in global crop production up to $30 \%$ by 2025, compared with the current grain yield of barley (Zhang, 2011). There are many studies that have reported a decreased plant growth and grain yield under drought stress conditions (Shao, Hong-Bo, et al., 2008) This reduction in growth and yield is subjective to be improved through many plant morphological 
and physiological mechanisms. Therefore, the current study was planned to evaluate the effect of drought stress and irrigated conditions on barley growth, grain filling duration, and grain related traits. Based on the results of current experiments, future research studies will be necessary to identify further key triats to develop drought tolerant genotypes of barley in the Garmian region.

\section{Materials and Methods}

2.1. Plant materials and experimental conditions

This study was carried out at Kalar technical institute for two seasons of 2016-17 (referred here ${ }^{-}$after as 2017) and 2017-18 (referred here ${ }^{-}$after as 2018). Five hybrid of $\mathrm{F}_{2}$ tow-rowed barley (Hordeum vulgare L.) were tested, namely Local//Zanbaka (3//18), Local//ARTa/3/Avar(3//14), Local//Roho/Zanbaka (3//5), Local//Avar/H/Sout (3//1) and Local//Tad mor/Roho (3//4) (Mahmood, 2010). Each experiment was carried out using a randomised block, split-plot design, in which two irrigation treatments (fully irrigated and unirrigated) were randomised on main-plots, and the five hybrids were randomised on sub-plots (1 $\mathrm{m} \times 1$ $\mathrm{m})$ with three replicates. The field experiments located at longitude line $45^{\circ} 22^{\prime}$ 681" eastern and latitude line $34^{\circ} 21^{\prime} 558^{\prime \prime}$ northern at the elevation level of 178 meters. The climate of the study region was semiarid with the soil of Aridisols, Hyperthermic temperature regime and Torric mo isture regime (Walter and Leith, 1960; Aziz, 2006; Kassim, 1989; Al-Taie, 1969). Water was added for the irrigated treatments when necessary based on the amount and the distribution of the rainfall precipitated in the region over the period of each season as shown in Figure 1.

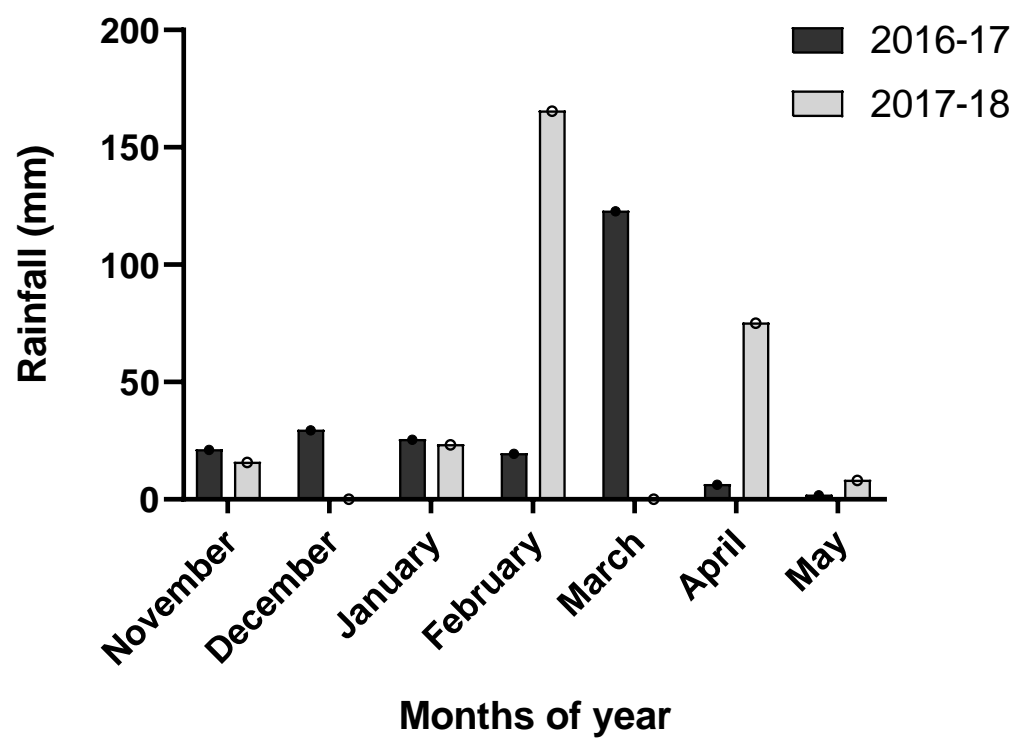

Fig. 1. Total monthly rainfall in Garmian region (Kalar) for both years (2016-17and 2017-18).

\subsection{Crop measurements}

2.2.1. Thousand Grain Weight (TGW; g)

In both experiments (2017 and 2018), all plants in each plot were hand-harvested at ground level after physiological maturity. The harvested materials were then separated into ears and straw. The ears were hand-threshed and five hundred grains were counted and weighed to obtain the 1000 grain weight.

2.2.2. Grain Filling Duration (GFD; $\left.{ }^{\circ} \mathrm{Cd}\right)$

In both seasons, anthesis date (GS61) and physiological maturity (GS89) were measured based on the decimal code of growth stages (GS) described by Zadoks et al. (1974). For GS61 a visual assessment for the whole plant in each sub-plot was carried out, and a growth stage was taken when more than $50 \%$ of the main shoots were at the anthesis date. Physiological maturity was assessed as the date when less than $25 \%$ of the stem area was remain ing green. Daily temperature (minimum and maximum) was also measured in order to calculate thermal time (average daily temperature (base temperature $0^{\circ} \mathrm{C}$ )). Grain Filling Duration 
$\left(\mathrm{GFD} ;{ }^{\circ} \mathrm{Cd}\right)$ was then calculated by accumulating thermal time of each day from anthesis to physiological maturity for each genotype.

\subsubsection{Grains number per decimetre spike (Grains/ds)}

At physiological maturity, five spikes per each sub-plot were randomly selected; spike length was measured and number of grains was also counted for each spike. Grains number for decimetre of spike was then calculated for each sub-plot.

\subsection{Statistical analysis}

For both years and cross-year mean data, GenStat 19th Edition (VSN International, 2017) was used for statistical analysis of variance (ANOVA) by applying a split-plot design. The GraphPad Pris m 8.0.0 software package was used for making graphs and linear reg ressions to calculate the relationships between all grains related variables in both years and for the cross-year mean (GraphPad Prism version 8.0.0, 2019).

\section{Results}

3.1. Thous and Grain Weight (TGW; g)

In 2017, drought decreased TGW from 82.43 to $72.66 \mathrm{~g}(P=0.02)$. Genotypes ranged from $75.00(3 / / 18)$ to $89.63 \mathrm{~g} \mathrm{(3//4)}$ under irrigated conditions, and 67.50 (3//18) to $77.63 \mathrm{~g} \mathrm{(3//4)} \mathrm{under} \mathrm{non} \mathrm{irrigated} \mathrm{condition}$ $(P=0.05)$. The irrigation $\mathrm{x}$ genotype interaction was not significant $(P=0.95$; Table 1$)$. In 2018 , drought reduced TGW slightly lower than 2017 from 79.00 to $73.49 \mathrm{~g}(P=0.04)$. Genotypes differed in the ranges $73.89(3 / / 1)$ to $85.11 \mathrm{~g}(3 / / 14)$ under irrigated conditions, and $70.30(3 / / 1)$ to $77.96(3 / / 14)$ under non irrigated condition $(\mathrm{P}=0.01)$. The irrigation $\mathrm{x}$ genotype interaction was not significant $(\mathrm{P}=0.96$; Table 1$)$. From the cross-year analysis, there was no effect of year on TGW $(\mathrm{P}=0.49)$. Drought reduced TGW from 80.71 to $73.08 \mathrm{~g}(\mathrm{P}=0.001)$. Genotypes differed in the range $76.55(3 / / 18)$ to $86.05 \mathrm{~g}(3 / / 14)$ under irrigated conditions, and $69.91(3 / / 18)$ to $76.65 \mathrm{~g}(3 / / 4)$ under unirrigated conditions $(\mathrm{P}=0.001)$. The irrigation $\mathrm{x}$ genotype $(\mathrm{P}=0.89)$ and year $\mathrm{x}$ genotype $(\mathrm{P}=0.35)$ interactions were not significant (Table 1).

Table 1. Mean, df and S.E.D. for thousand grain weight (TGW; g) under irrigated and unirrigated conditions for 5 genotypes of barley in 2017, 2018 and cross-year mean.

\begin{tabular}{|c|c|c|c|c|c|c|}
\hline \multirow{2}{*}{ Genotypes } & \multicolumn{2}{|l|}{2017} & \multicolumn{2}{|l|}{2018} & \multicolumn{2}{|l|}{$2017-18$} \\
\hline & Irrigated & Unirrigated & Irrigated & Unirrigated & Irrigated & Unirrigated \\
\hline $3 / / 18$ & 75.00 & 67.50 & 78.10 & 72.31 & 76.55 & 69.91 \\
\hline $3 / / 14$ & 87.00 & 74.93 & 85.11 & 77.96 & 86.05 & 76.44 \\
\hline $3 / / 5$ & 79.88 & 69.38 & 75.55 & 71.22 & 77.71 & 70.30 \\
\hline $3 / / 1$ & 80.63 & 73.88 & 73.89 & 70.30 & 77.26 & 72.09 \\
\hline $3 / / 4$ & 89.63 & 77.63 & 82.35 & 75.68 & 85.99 & 76.65 \\
\hline Mean & 82.43 & 72.66 & 79.00 & 73.49 & 80.71 & 73.08 \\
\hline \multicolumn{7}{|l|}{ SED (df) } \\
\hline Year (1) & & & & & $1.778^{\mathrm{ns}}$ & \\
\hline Irrigation (1) & $1.94^{*}$ & & $1.498^{*}$ & & $1.227^{* *}$ & \\
\hline Genotype (4) & $4.15^{*}$ & & $2.77^{* *}$ & & $2.497^{* *}$ & \\
\hline Irri. x Gen. (4) & $5.60^{\mathrm{ns}}$ & & $3.811^{\mathrm{ns}}$ & & $3.388^{\text {ns }}$ & \\
\hline Year x Gen. (4) & & & & & $3.624^{\mathrm{ns}}$ & \\
\hline
\end{tabular}

N.B: ${ }^{* * * *}$ denotes $\mathrm{P}<0.001 ;{ }^{* *} \mathrm{P}<0.01$ and ${ }^{*} \mathrm{P}<0.05$ significance levels; ${ }^{\text {ns }}=$ not significant.

\subsection{Grain Filling Duration (GFD; $\left.{ }^{\circ} \mathrm{Cd}\right)$}

In 2017, there was no significant drought effect on grain filling duration $(\mathrm{P}=0.55)$. Genotypes ranged from 657.0 (3//18) to $747.5{ }^{\circ} \mathrm{Cd}(3 / / 14)$ under irrigated conditions, and from 650.1 (3//18) to $711.3{ }^{\circ} \mathrm{Cd}(3 / / 4)$ under unirrigated conditions $(\mathrm{P}=0.002)$. The irrigation $x$ genotype interaction was not significant $(\mathrm{P}=0.24$; Table 2). In 2018, drought advanced the physiological maturity from 720.4 to $641.9{ }^{\circ} \mathrm{Cd}(\mathrm{P}=0.01)$. Genotypes differed in the range $702.8(3 / / 5)$ to $752.3{ }^{\circ} \mathrm{Cd}(3 / / 18)$ and $596.9(3 / / 1)$ to $674.8^{\circ} \mathrm{Cd}(3 / / 14)$ 
under irrigated and unirrigated conditions, respectively $(\mathrm{P}=0.04$; Table 2). Averaging over seasons, Drought reduced grain filling duration from 709.2 to $664.9^{\circ} \mathrm{Cd}(\mathrm{P}=0.005)$. Genotypes ranged from 686.0 (3//1) to $732.0^{\circ} \mathrm{Cd}(3 / / 4)$ and from $648.9(3 / / 1)$ to $687.1{ }^{\circ} \mathrm{Cd}(3 / / 14)$ under irrigated and drought conditions, respectively $(\mathrm{P}=0.004)$. There was significant year $\mathrm{x}$ genotype interaction $(\mathrm{P}=0.004)$, but not irrigation $\mathrm{x}$ genotype $(\mathrm{P}=0.96$; Table 2$)$.

Grain filling duration showed a strong positive linear relationship with thousand grain weight amongst genotypes in 2017 under both irrigated and unirrigated conditions $\left(\mathrm{R}^{2}=0.85 ; \mathrm{P}=0.03\right.$ and $\mathrm{R}^{2}=0.91 ; \mathrm{P}=0.01$, respectively; Figure 2a). Under unirrigated, there was a trend for a positive relationship in 2018 between thousand grain weight and grain filling duration $\left(\mathrm{R}^{2}=0.61 ; \mathrm{P}=0.12\right)$, but not under irrigated condition $\left(\mathrm{R}^{2}=0.05 ; \mathrm{P}=0.73\right.$; Figure $\left.2 \mathrm{~b}\right)$. Averaging across years, a positive linear relationship between grain filling duration and thousand grain weight amongst genotypes was also found under both irrigated $\left(\mathrm{R}^{2}=0.85\right.$; $\mathrm{P}=0.03)$ and unirrigated $\left(\mathrm{R}^{2}=0.80 ; \mathrm{P}=0.04\right.$; Figure $\left.2 \mathrm{c}\right)$ conditions.

Table 2. Mean, df and S.E.D. for grain filling duration (GFD; $\left.{ }^{\circ} \mathrm{Cd}\right)$ under irrigated and unirrigated conditions for 5 genotypes of barley in 2017, 2018 and cross-year mean.

\begin{tabular}{|lllllll|}
\hline \multirow{2}{*}{ Genotypes } & 2017 & \multicolumn{3}{c|}{2018} \\
\cline { 2 - 7 } & Irrigated & Unirrigated & Irrigated & Unirrigated & Irrigated & Unirrigated \\
\hline $3 / / 18$ & 657.0 & 650.1 & 752.3 & 660.6 & 704.6 & 655.4 \\
$3 / / 14$ & 747.5 & 699.5 & 710.0 & 674.8 & 728.8 & 687.1 \\
$3 / / 5$ & 686.0 & 678.1 & 702.8 & 631.4 & 694.4 & 654.8 \\
$3 / / 1$ & 666.8 & 701.0 & 705.3 & 596.9 & 686.0 & 648.9 \\
$3 / / 4$ & 732.3 & 711.3 & 731.8 & 645.6 & 732.0 & 678.4 \\
Mean & 697.9 & 688.0 & 720.4 & 641.9 & 709.2 & 664.9 \\
\hline SED (df) & & & & & & \\
Year (1) & & & & & $16.18^{\text {ns }}$ & \\
Irrigation (1) & $14.57^{\text {ns }}$ & & $14.53^{* *}$ & & $10.29^{* *}$ & \\
Genotype (4) & $17.33^{* *}$ & & $17.64^{*}$ & & $12.37^{* *}$ & \\
Irri. x Gen. (4) & $26.32^{\text {ns }}$ & & $26.63^{\text {ns }}$ & & $22.50^{* *}$ & \\
Year x Gen. (4) & & & & & & \\
\hline
\end{tabular}

N.B: ${ }^{* * * *}$ denotes $\mathrm{P}<0.001 ;{ }^{* *} \mathrm{P}<0.01$ and ${ }^{*} \mathrm{P}<0.05$ significance levels; ${ }^{\mathrm{ns}}=$ not significant. 
(a) 2017

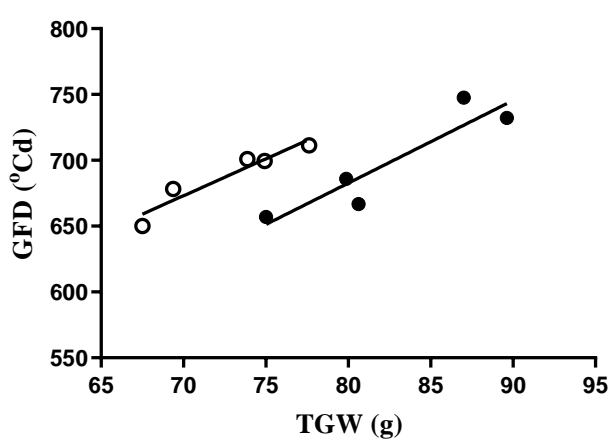

(c) 2017-2018

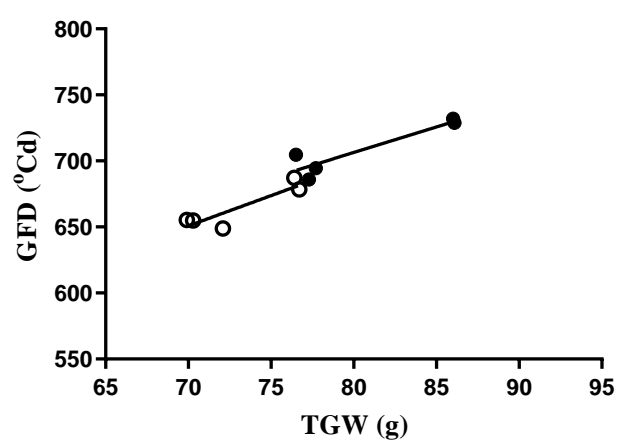

(b) 2018

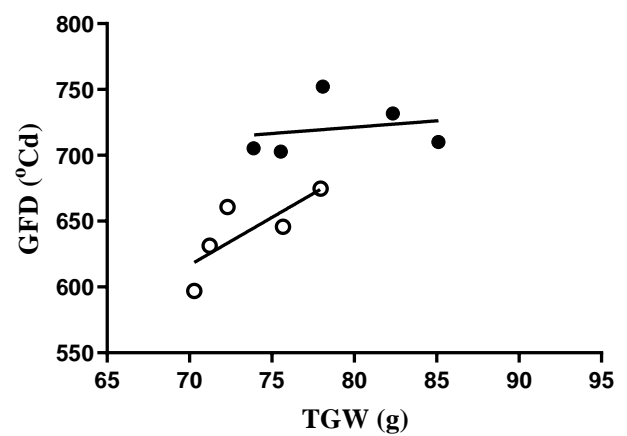

Irrigated

Unirrigated

(a)

$Y=6.280^{*} X+180.3$

$Y=5.608^{*} X+280.5$

$R^{2}=0.85 ; P=0.03$

$R^{2}=0.91 ; P=0.01$

(b)

$Y=0.9614^{*} X+644.5$

$Y=7.244^{*} X+109.5$

$R^{2}=0.05 ; P=0.73$

$R^{2}=0.61 ; P=0.12$

(c)

$Y=3.869^{*} X+396.9$
$R^{2}=0.85 ; P=0.03$

$Y=4.578^{*} X+330.3$

$R^{2}=0.80 ; P=0.04$

Fig. 2. Linear regressions of thousand grain weight (TGW; g) on grain filling duration (GFD; ${ }^{\circ} \mathrm{Cd}$ ) for 5 genotypes of barley in (a) 2017, (b) 2018 and (c) cross-year mean under irrigated and unirrigated conditions.

\subsection{Grains number per decimetre spike (Grains/ds)}

There was no effect of drought on this parameter in both $2017(\mathrm{P}=0.96)$ and $2018(\mathrm{P}=0.85)$, and cross -year mean $(\mathrm{P}=0.89)$. However, in 2017 , genotypes significantly differed from 32.81 (3//4) to $34.79(3 / / 5)$ under irrigated, and from 32.27 (3//14) to 36.05 (3//5) under unirrigated conditions $(\mathrm{P}=0.05)$. In 2018, genotypes ranged from $31.43(3 / / 14)$ to $34.99(3 / / 1)$, and from 32.44 (3//4) to $34.20(3 / / 1)$ under irrigated and unirrigated conditions, respectively $(\mathrm{P}=0.05)$. For the cross -year mean, genotype $(3 / / 5)$ scored the highest number of grain under both irrigated and unirrigated conditions (34.79 and 34.74, respectively), while genotype (3//14) under irrigated and (3//4) under unirrigated scored the lowest (32.63 and 32.50, respectively) $(\mathrm{P}=0.003)$. The irrigation $\mathrm{x}$ genotype interaction was not significant for both years 2017 and 2018 , and cross-year mean $(\mathrm{P}=0.65, \mathrm{P}=0.35$ and $\mathrm{P}=0.89$, respectively; Table 3$)$.

Regression analysis showed a trend for a negative relationship between thousand grain weight and grain number in 2017 under both irrigated and unirrigated conditions $\left(\mathrm{R}^{2}=0.64 ; \mathrm{P}=0.11\right.$ and $\mathrm{R}^{2}=0.70 ; \mathrm{P}=0.08$, respectively; Figure 3a). In 2018, the relationship was weak under both irrigated and non irrigated condition $\left(\mathrm{R}^{2}=0.20 ; \mathrm{P}=0.44\right.$ and $\mathrm{R}^{2}=0.43 ; \mathrm{P}=0.23$, respectively; Figure $\left.3 \mathrm{~b}\right)$. However, for the cross -year mean, a significant negative correlation was found between thous and grain weight and grain number under unirrigated conditions $\left(\mathrm{R}^{2}=0.75 ; \mathrm{P}=0.05\right)$, but not underirrigated conditions $\left(\mathrm{R}^{2}=0.43 ; \mathrm{P}=0.23\right.$; Figure $\left.3 \mathrm{c}\right)$. 
Table 3. Mean, df and S.E.D. for number of grains per decimetre spike (Grains/ds) under irrigated and unirrigated conditions for 5 genotypes of barley in 2017, 2018 and cross -year mean.

\begin{tabular}{|lllllll|}
\hline \multirow{2}{*}{ Genotypes } & 2017 & \multicolumn{3}{c|}{$2017-18$} \\
\cline { 2 - 7 } & Irrigated & Unirrigated & Irrigated & Unirrigated & Irrigated & Unirrigated \\
\hline $3 / / 18$ & 34.29 & 34.77 & 33.29 & 34.01 & 33.79 & 34.39 \\
$3 / / 14$ & 33.84 & 32.27 & 31.43 & 33.02 & 32.63 & 32.64 \\
$3 / / 5$ & 34.79 & 36.05 & 34.79 & 33.42 & 34.79 & 34.74 \\
$3 / / 1$ & 34.24 & 34.02 & 34.99 & 34.20 & 34.62 & 34.11 \\
$3 / / 4$ & 32.81 & 32.56 & 33.31 & 32.44 & 33.06 & 32.50 \\
Mean & 33.99 & 33.93 & 33.56 & 33.42 & 33.78 & 33.68 \\
\hline SED (df) & & & & & & $0.361^{\mathrm{ns}}$ \\
Year (1) & & & & & $0.698^{\mathrm{ns}}$ & \\
Irrigation (1) & $1.201^{\mathrm{ns}}$ & & $0.711^{\mathrm{ns}}$ & & $0.622^{* *}$ & \\
Genotype (4) & $0.943^{*}$ & & $0.813^{*}$ & & $1.052^{\mathrm{ns}}$ & \\
Irri. x Gen. (4) & $1.692^{\mathrm{ns}}$ & & $1.250^{\mathrm{ns}}$ & & $0.866^{\mathrm{ns}}$ & \\
Year x Gen. (4) & & & & & & \\
\hline
\end{tabular}

N.B: ${ }^{* * *}$ denotes $\mathrm{P}<0.001 ;{ }^{* *} \mathrm{P}<0.01$ and ${ }^{*} \mathrm{P}<0.05$ significance levels; ${ }^{\mathrm{ns}}=$ not significant.

(a) 2017

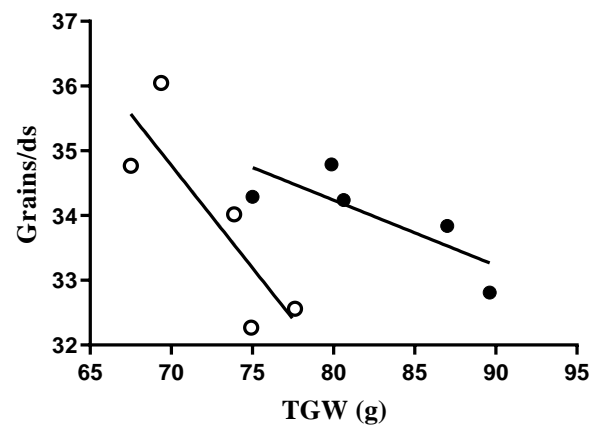

(c) $2017-2018$

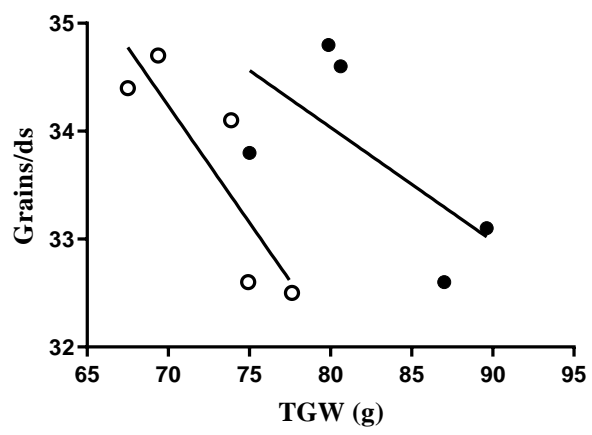

(b) 2018

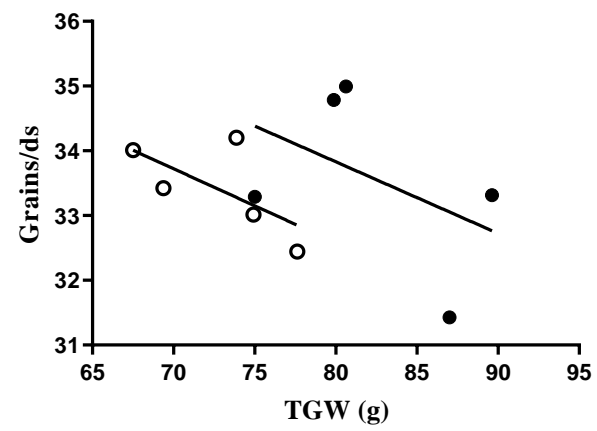

Irrigated

Unirrigated
(a) $\mathrm{Y}=-0.1010^{*} \mathrm{X}+42.32$
$Y=-0.3167^{*} X+56.95$
$R^{2}=0.64 ; P=0.11$
$R^{2}=0.70 ; P=0.08$
(b) $Y=-0.1106^{*} X+42.68$
$Y=-0.1144^{\star} X+41.73$
$R^{2}=0.20 ; P=0.44$
$R^{2}=0.43 ; P=0.23$
(c) $Y=-0.1055^{*} X+42.47$
$\mathrm{Y}=-0.2164^{\star} \mathrm{X}+49.38$
$R^{2}=0.43 ; P=0.23$
$R^{2}=0.75 ; P=0.05$

Fig. 3. Linear regressions of thousand grain weight (TGW;g) on grains number per decimetre spike (Grains/ds) for 5 genotypes of barley in (a) 2017, (b) 2018 and (c) cross-year mean under irrigated and unirrigated conditions. 
4. Discussions

In this study, drought was severer in 2018 than in 2017 as drought occuerd mostly over the period of g rain filling duration in 2018 (shown in figure 1). Averaging over years, genotype $3 / / 14$ and $3 / / 4$ gave the highest value of thousand grain weight under both irrigated and unirrigated conditions while $3 / / 1$ lost the least grain weight under drought because of the ability of th is genotype to be least affected by drought stress and have relatively longer grain filling duration under drought conditions. Under drought stress different genetic materials of barley have been investigated and showed significant difference between them (Maisa, et al, 2013).

There was a positive relationship between TGW and GFD due to have longer time to fill the grains and consequently produce heavier single grain and then thousand grain weight (Ku mari, et al, 2013). There was a negative correlation between TGW and grains/ds (i.e. more grains on the spike less weight gain of the grains) showing the effect of source-sink due to the trade-off between number of grains and grains weight on the spike (Serrago, et al, 2013). Grain growth process, in this study, was appeared mainly affected by restricting soil moisture availability through reducing grain filling durations and consequently reduct ion in thous and grain weight.

\section{Conclusions}

Water deficit did not appear to affect grain number as this trait is introduced to be genetically controlled. The physiological mechanisms between grain related traits appeared to be explained through two different directions of relationship. A positive association between thous and grain weight and grain filling duration under both irrigated and unirrigated conditions averaging over seasons indicated that elongating postanthesis period gave adequate time to increase the single grain weight. However, the co rrelation between thousand grain weight and grains number was negative for drought conditions may due to the trade-off between these two traits.

\section{References}

Algebra, F. I; MZ. Hussain; S. Aishia; and Daur I. (2015). Effect of Rht alleles on wheat grain yield and quality under high temperature and drought stress during booting and anthesis. Environ. Sci. Pollut. Res. 22:15506-15515.

Al-Taie, F. H.; C. Sycand and J. Stoops (1969). Soil g roups of Iraq, their classification and characteristics pedologie, 19:65-148.

Aziz, S. N. (2006). Survey and classification of some soils from Kurdistan region. M.Sc. thesis submitted to the university of Sulaimani, college of agriculture.

Dimova, D., Valcheva, D., S. Zapranov and G. Mihova, (2006). Ecological plasticity and s tability in the yield of winter barley varieties, Jubilee conference 65 years agrarian science in Dobrudzha. Field Crop Studies, 3 (2): 197-203.

Evans, L. T. and I. F. Wardlaw, (1976). Aspects of the comparative physiology of grain yield in cereals, Academic Press, New York. Advance in Agronomy, 28: 301-359.

GraphPad Prism version 8.0.0 for Windows (2019), Linear regression analysis was performed using graphPad Software, San Diego, California USA, www.graphpad.com.

Helbaek, h. (1953). Archaeology and agricultural botany. Ann. Rept. Inst. Archaeol. pp. 45-59, illus. London.

Kassim, J. K.; K. Z. Al-Janabi and M. I. Karim (1989). Soil temperature regimes in Iraq: II-Relationships between soil temperature and latitude, longitude and elevation. J. Agri. Water Res o. Res. 8(1):111-121.

Kumari, M. (2013). Association of staygreen trait with canopy temperature depression and yield traits under terminal heat stress in wheat (Triticum aestivum L.). Euphytica 190.1: 87-97.

Linear regression analysis was performed using GraphPad Pris m version 8.0.0 for Windows (2019), GraphPad Software, San Diego, California USA, www.graphpad.com.

Mahmood, Y. A. (2010). Full Diallel Crosses in Two-rowed Barley (Hordeum vulgare L.). M.Sc. thesis submitted to the university of Sulaimani, college of agriculture.

Maisa'a, F., Adel H. Abdel-Ghani, and Nedal F. Al-Majali. (2013). Response of barely varieties to drought stress imposed at different developmental stages. Jordan Journal of Agricultural Sciences 9.4.

Penchev, P. and V. Koteva, (2002). Impact of agro-meteorological conditions on productivity of winter forage barley. Selection and Agro Technology Arable Crops, 2: 517-522. 
Rasmussen, D. C. and R. Q. Chanel, (1970). Selection for grain yield and components of yield in barley. Crop Science, 10: 51-54.

Reid, D.A. \& G.A. Wiebe, 1979. Toxonomy, botany, classification, and world collection, pp. 78-103. In: USDA, USA (Eds). Barley-Agricultural Handbook No. 338, Washington D.C.

Serrago, R. (2013). Understanding grain yield responses to source-sink ratios during grain filling in wheat and barley under contrasting environments. Field Crops Research 150: 42-51.

Shao, Hong-Bo, et al. "Water-deficit stress-induced anatomical changes in higher plants." Comptes rendus biologies 331.3 (2008): 215-225.

Sinebo, W., (2002). Determination of grain protein concentration in barley: Yield relationship of barleys grown in a tropical highland environment. Crop Science Journal, 24: 428-437.

VSN International (2017). Genstat for Windows 19th Edition. VSN International, Hemel Hempstead, UK. Walter, H. and H. Leith (1960). Climadigram welt atlas. Jena, 4: 434.

Zadoks JC, Chang TT, Kon zak CF. (1974). A decimal code for the growth stages of cereals. Weed research $14,415-421$.

Zhang J (2011). China's success in increasing per capita food production. J. Exp. Bot. 62: 3707-3711. 